\title{
EFICIENCIA EN ASIGNACIÓN DE CUOTAS INDIVIDUALES DE PESCA: TEOREMA DE COASE Y ASIMETRÍAS DE INFORMACIÓN
}

\author{
Eduardo Saavedra \\ Ilades - Universidad Alberto Hurtado \\ Manuel Willington \\ Universidad Adolfo Ibáñez
}

\begin{abstract}
Resumen: Este trabajo muestra que la asignación inicial de las cuotas individuales de pesca mediante una subasta garantiza la eficiencia económica, lo que no sucede necesariamente, sin embargo, cuando la asignación es por criterios históricos. El argumento central es que el teorema de Coase es inapropiado ante asimetrías de información, aun con costos de transacción nulos. Una aplicación directa del teorema de Myerson-Satterthwaite plantea que la asignación inicial de estas cuotas sí importa, generándose un sesgo en la asigna-
\end{abstract}

Eduardo SaAVedra. Ingeniero Comercial, Universidad de Chile y Ph.D. en Economía, Cornell University. Académico de Ilades - Universidad Alberto Hurtado (saavedra@uahurtado.cl).

Manuel Willington. Economista, Universidad Nacional de Córdoba y Ph.D. en Economía, University of Pennsylvania. Académico de la Escuela de Gobierno, Universidad Adolfo Ibáñez (manuel.willington@uai.cl).

* Trabajo basado en informe presentado al Tribunal de Defensa de la Libre Competencia, el que fue financiado por Lota Protein S.A. Se agradecen los comentarios de dos árbitros anónimos de Estudios Públicos, no obstante los autores son los únicos responsables de las opiniones vertidas en este trabajo. 
ción final hacia quien tiene el derecho de propiedad inicial. Desde la perspectiva de política pública, resulta fundamental asegurar que las cuotas de pesca iniciales sean asignadas eficientemente, lo que sólo podría garantizarse con una subasta adecuadamente diseñada.

Palabras clave: cuotas de pesca, transacción, información, Coase, Myerson-Satterthwaite.

Clasificación JEL: D23, D82, K23, L78, Q22.

Recibido: abril 2012; aceptado: julio 2012.

\section{EFFICIENT ALLOCATION OF INDIVIDUAL FISHING QUOTAS: COASE THEOREM AND ASYMMETRIC INFORMATION}

Abstract: This paper shows that the initial allocation of individual fishing quotas through auctions guarantee economic efficiency. This result is not necessarily true when the assignment is made by historical criteria. The central argument is that the Coase theorem (even in its weak version) is inappropriate when there are information asymmetries, even with zero transaction costs. A direct application of the Myerson-Satterthwaite theorem states that the initial allocation of these fishing rights does matter, generating a bias in the final allocation favorable to whom has the initial property right. From the public policy point of view, it is essential to ensure an efficient allocation of the initial fishing quotas, which could only be guaranteed with a properly designed auction.

Keywords: fishing quotas, transaction, information, Coase, Myerson-Satterthwaite.

JEL Codes: D23, D82, K23, L78, Q22.

Received: April 2012; accepted: July 2012.

\section{Introducción}

$\mathrm{P}$ róxima a expirar la llamada "ley corta" sobre asignaciones de cuotas individuales de pesca, en diciembre de 2012, se ha generado un extenso debate que llegó hasta el Tribunal de Defensa de la Libre Competencia (TDLC), en lo particular respecto de cómo se norma la asignación de estas cuotas en la nueva ley. Las principales pesquerías afectas al régimen de cuotas (Límite Máximo de Captura por Armador [LMCA]), y que son el foco de este trabajo, son las de anchoveta, jurel 
y sardina común, siendo el principal uso de estos recursos su reducción para la elaboración de harina y aceite de pescado. Por tratarse de un proceso no contencioso, el TDLC se pronunció mediante la Proposición $\mathrm{N}^{\mathrm{o}} 12$, en la que recomienda una serie de medidas tendientes, fundamentalmente, a facilitar la transferibilidad de las cuotas de pesca entre industriales.

Este artículo analiza desde la perspectiva económica el criterio de asignación inicial de las cuotas individuales de pesca, entendiendo que hay dos visiones en contraposición: asignar administrativamente de acuerdo a criterios históricos o propiciar un mecanismo de asignación mediante una subasta ${ }^{1}$. En el análisis de estas alternativas se da por sentado una serie de temas que son independientes del mecanismo de asignación inicial de cuotas individuales de pesca, como la transferibilidad (imperfecta pero perfectible) de éstas, el mecanismo de recaudación fiscal por las cuotas asignadas o la posibilidad de cooperación entre industriales en las actividades de pesca. Estos otros temas propios también del debate público quedan fuera de nuestro análisis ${ }^{2}$.

Es importante destacar que el enfoque de este artículo es exclusivamente económico y parte de un supuesto fundamental, aunque ciertamente debatible: los derechos de pesca no están asignados y es el Estado el responsable de definir cómo hacerlo. Es decir, el artículo no analiza desde una perspectiva legal si quienes actualmente poseen los derechos de pesca tienen derechos que van más allá del 2012. Si así fuera, el re-asignar los derechos de propiedad (vía subasta o por otro medio, pero no de acuerdo a criterio histórico) implicaría antes una expropiación de derechos cuyas consecuencias económicas, naturalmente, serían muy diferentes a las de una asignación inicial de derechos de propiedad por criterios diferentes a los históricos.

Hay dos elementos que, como se verá, debieran ser centrales en la discusión sobre la conveniencia de licitar versus asignar administra-

${ }^{1}$ En particular, Montero (2010) establece la irrelevancia del mecanismo de asignación de estas cuotas en materia de eficiencia en la asignación de recursos, particularmente basado en su no observación de poder de mercado por parte de los productores nacionales y de observar bajos niveles de costos de transacción en la industria. Por el contrario, Villena, Niño y Zechetti (2010) mencionan que el arrendamiento de cuotas reflejaría que los costos de transacción en esta industria son relevantes, lo que haría también relevante el cómo los derechos de extracción se asignen originalmente.

2 Para una revisión de los fundamentos económicos de la regulación del sector y su implementación en Chile, véase Peña-Torres (2002). 
tivamente las cuotas: la existencia de "costos de transacción" y de "asimetrías de información". Lamentablemente, el debate se ha centrado casi exclusivamente en el primero de estos elementos ignorándose en buena medida el segundo. ¿A qué se refieren los economistas cuando hablan de "asimetrías de información"? Simplemente a circunstancias en las que los diferentes actores involucrados en una posible transacción (en este caso el Estado y las empresas pesqueras, actuales y potenciales entrantes) tienen diferentes estimaciones sobre variables relevantes que determinan el valor del objeto a transar como pueden ser, en el caso que nos ocupa, la evolución futura del recurso pesquero, de la fijación de la cuota, de los costos de extracción de cada una de las partes, de procesamiento, etc.

Es pertinente precisar que no es en absoluto condición necesaria para la existencia de asimetrías de información que el bien a transar sea descrito de manera imperfecta; ambas partes pueden conocer perfectamente las características del bien a transar (v.g., el derecho a pescar un determinado porcentaje de la cuota global de un determinado recurso) y aun así existir asimetrías de información que dificultan las transacciones. Este ciertamente podría ser el caso si, por ejemplo, sólo una de las partes tuviera incertidumbre respecto al valor de una variable que la otra conoce (la calidad de un automóvil usado en Akerlof, 1970), pero el caso más general es aquél en donde cada parte tiene estimaciones diferentes respecto a distintas variables relevantes (por ejemplo, los costos de producción propios) y, por lo tanto, las asimetrías no son a favor ni en contra de ninguna de las partes.

El menoscabo en la discusión por el rol de las asimetrías de información no es neutral al análisis, ya que la relevancia de las subastas como mecanismo de asignación (sea de una cuota de pesca, de un cuadro de Picasso o de la concesión de cualquier obra) surge precisamente por la existencia de asimetrías de información. En efecto, si el propietario de un cuadro quisiera venderlo y conociese cuánto lo valora cada uno de los potenciales compradores, entonces no lo subastaría sino que simplemente se acercaría a negociar con quien más lo valora y, de este modo, se ahorraría la comisión del martillero o los costos de organizar la subasta ${ }^{3}$. Las subastas, en sus diversos formatos y con las necesarias

${ }^{3}$ En el caso de transacciones en la que el Estado es parte, una segunda razón - tanto o más importante que la primera - por la cual las subastas son tan populares tiene que ver con motivos de transparencia. 
consideraciones de las peculiaridades de cada transacción, son el mejor mecanismo conocido para asignar recursos eficientemente en contextos de asimetrías de información ${ }^{4}$.

El argumento a favor de la asignación por vía administrativa se basa en el celebrado teorema de Coase, el que establece que en ausencia de costos de transacción la asignación inicial de derechos de propiedad es irrelevante desde el punto de vista de la eficiencia económica, ya que las partes se pondrán de acuerdo y transarán los distintos bienes hasta llegar a una asignación eficiente. En otras palabras, se restaurarían las condiciones para la aplicación del Primer Teorema Fundamental del Bienestar.

Es importante subrayar tres elementos esenciales del teorema. En primer lugar, el teorema se refiere exclusivamente a consideraciones de eficiencia económica y excluye, por lo tanto, consideraciones de orden distributivas que pueden ser relevantes en la discusión. ¿Por qué asignar por vía administrativa y sin costo para los beneficiarios las cuotas individuales de pesca cuando podrían obtenerse recursos para el Estado? Puede argumentarse que por derechos históricos asociados a inversiones realizadas o que en lugar de generarse recursos ex ante mediante la subasta podrían generarse ex post cobrando algún tipo de gravamen especial. Estos son argumentos potencialmente válidos y deben incluirse en el debate general. El foco en este trabajo está restringido sólo al de la eficiencia económica, por lo que se excluyen del análisis las consideraciones distributivas.

El segundo elemento se refiere a la validez del teorema. En contextos en que existen asimetrías de información, Myerson y Satterthwaite (1983) demostraron que el teorema de Coase simplemente no es válido y, por lo tanto, la asignación inicial de bienes sí es relevante desde la perspectiva de eficiencia económica. En efecto, mientras el teorema de Coase fue escrito en el contexto de información completa a principios de los años 60, el teorema de Myerson-Satterhwaite (1983) manifiesta que es imposible que exista un mecanismo eficiente de transacción ex post cuando se está en presencia de información incompleta o asimétrica. En consecuencia, aun cuando pueda ser cierto que las

${ }^{4}$ Las asimetrías de información llevan en general a mercados incompletos, lo cual invalida el Primer Teorema Fundamental del Bienestar (ver como referencia exhaustiva Magill y Quinzii, 1996). Por ello, una asignación inicial eficiente es de suma importancia y una subasta bien diseñada puede asegurarla. 
ventajas de información que pueden tener los pescadores ya establecidos no provengan de comportamientos contrarios a la libre competencia, dada la existencia de estas asimetrías de información, sería temerario sugerir que la asignación inicial de las cuotas que realice el legislador es irrelevante desde el punto de vista de la eficiencia económica, basados en argumentos de inexistencia de costos de transacción solamente.

El tercer y último elemento se refiere también a la relevancia práctica del teorema de Coase dada la omnipresencia de los costos de transacción. A decir del propio Coase:

[E]ntiendo el teorema de Coase como un punto de partida para el estudio de un mundo con costos de transacción. El significado para mí del teorema de Coase es que resta validez al sistema Pigouviano. Puesto que la teoría económica estándar supone que los costos de transacción son cero, el teorema de Coase demuestra que en estas circunstancias las soluciones pigouvianas son innecesarias 5 . Por supuesto, ello no implica que, cuando los costos de transacción son positivos, las acciones del gobierno (intervenciones del gobierno, regulaciones, impuestos y subsidios) no puedan llevar a mejores resultados que los que resultarían de negociaciones entre los individuos. Si esto es así no es algo que pueda descubrirse estudiando gobiernos imaginarios, sino que debe estudiarse lo que los gobiernos hacen en realidad. Mi conclusión: estudiemos el mundo con costos de transacción positivos ${ }^{6}$.

Es importante destacar que la discusión anterior se relaciona directamente a potenciales problemas de eficiencia productiva (que los más eficientes sean efectivamente quienes producen) y es independiente de si el origen de los costos de transacción y asimetrías de información se relaciona o no con actividades contrarias a la libre competencia. Un análisis complementario, que escapa el objetivo de este trabajo, sería el del posible ejercicio de poder de mercado por parte de los cuota-habientes y sus consecuencias en términos de eficiencia asignativa.

El aporte de este artículo es clarificar el (mal) uso que regularmente se le da al teorema de Coase en el debate académico acerca de

${ }^{5}$ La solución pigouviana se refiere a la recomendación de corregir la existencia de externalidades mediante la imposición de impuestos o subsidios específicos.

${ }^{6}$ Traducción de los autores a partir de Coase (1992), p. 717. 
las bondades o falencias de una u otra política pública, en este caso particular la asignación de las cuotas individuales de pesca. En la siguiente sección se describe brevemente el sector pesquero, en particular en lo que se refiere a la importancia a nivel global que tiene Chile como oferente y demandante del sector y la evolución del sector pesquero industrial sujeto a cuotas individuales de pesca en los últimos años. Esta descripción permite vislumbrar una industria altamente concentrada en la pesca industrial a nivel nacional, con creciente integración vertical hacia la actividad acuícola y la casi nula actividad de compra-venta genuina de cuotas individuales de pesca en los últimos años. En la sección 3 se discute en profundidad la relevancia de los costos de transacción y de las asimetrías de información y, por lo tanto, del teorema de Coase. Adicionalmente, se discute el rol de las subastas como posible mecanismo de asignación de las cuotas de pesca. En la sección 4 se presentan reflexiones de política pública en torno a este problema. Finalmente, la sección 5 concluye.

\section{Descripción del sector}

\subsection{Importancia global de Chile}

La producción de harina y aceite de pescado. Según información de The International Fishmeal and Fish Oil Organisation (IFFO) e ISTA Mielke GmbH (www.oilworld.de), la producción mundial de harina de pescado durante el año 2009 fue de 4.775.200 ton. El mayor productor a nivel mundial de harina de pescado es Perú, con una producción de 1.346 .900 toneladas correspondiendo al $28 \%$ de la producción mundial. El segundo productor a nivel mundial es Chile con una producción de 641.000 ton, correspondiente al 13\% de la producción mundial. Perú es también el mayor exportador de harina de pescado, representando el $44 \%$ de todas las exportaciones evidenciadas durante el año 2009 en tanto que Chile le sigue en segundo lugar con exportaciones por 609.300 toneladas, alrededor del $17 \%$ de las exportaciones mundiales.

Similar situación se observa al analizar la producción mundial de aceite de pescado. Durante el año 2009 la producción mundial de aceite de pescado ascendió a 1.017.000 ton. El mayor productor a nivel mundial de aceite de pescado es Perú, con una producción de 258.400 
toneladas correspondiendo al 25\% de la producción mundial. El segundo productor a nivel mundial es Chile con una producción de 152.800 ton, correspondiente al $15 \%$ de la producción mundial. En este mercado Perú también es el mayor exportador a nivel mundial, exportando prácticamente la totalidad de su producción, representando el $32 \%$ de todas las exportaciones evidenciadas durante el año 2009. Le sigue Dinamarca e Islandia con un 13\% y un $9 \%$ de las exportaciones mundiales respectivamente. Chile se encuentra en el cuarto lugar con exportaciones por 80.800 toneladas, representando sólo el $9 \%$ de las exportaciones mundiales (hecho que se explica por la importancia del consumo local).

La importancia de Chile como productor y exportador de harina de pescado y aceite de pescado a nivel mundial es evidente también al analizarse el efecto que tuvo el terremoto de febrero de 2010, que afectó principalmente al sur de Chile, en la evolución de los precios internacionales. Como ilustra la Figura $\mathrm{N}^{\circ}$ 1, luego del terremoto del 27 de febrero de 2010 el precio de la harina de pescado (en US\$/ton) escaló a su valor más alto en toda su historia, alcanzando los US\$1.961/ton en abril de este año, casi un $86 \%$ superior a igual mes del año pasado.

FIGURA $N^{\circ}$ 1: $\quad$ PRECIO HARINA DE PESCADO

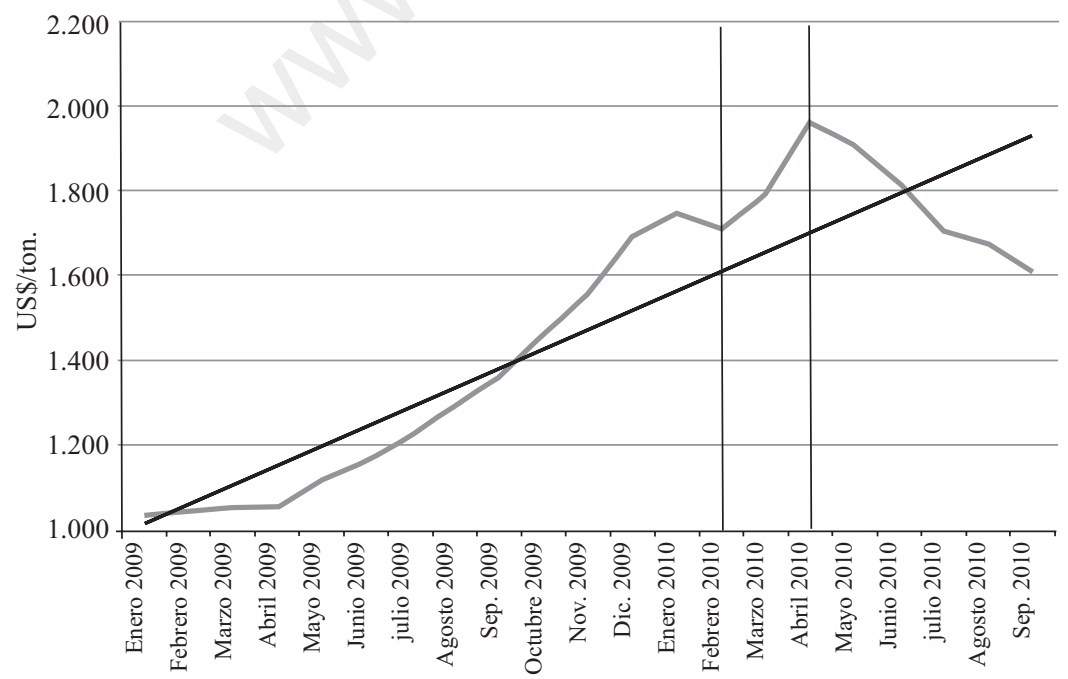

Nota: Harina de pescado de Perú / pellets $65 \%$ proteína - CIF US\$/Ton.

Fuente: Fondo Monetario Internacional. 
FIGURA N ${ }^{\circ}$ 2: $\quad$ PRECIO ACEITE DE PESCADO

(CUALQUIER ORIGEN - CIF NOR-OESTE DE EUROPA, US\$/TON.)

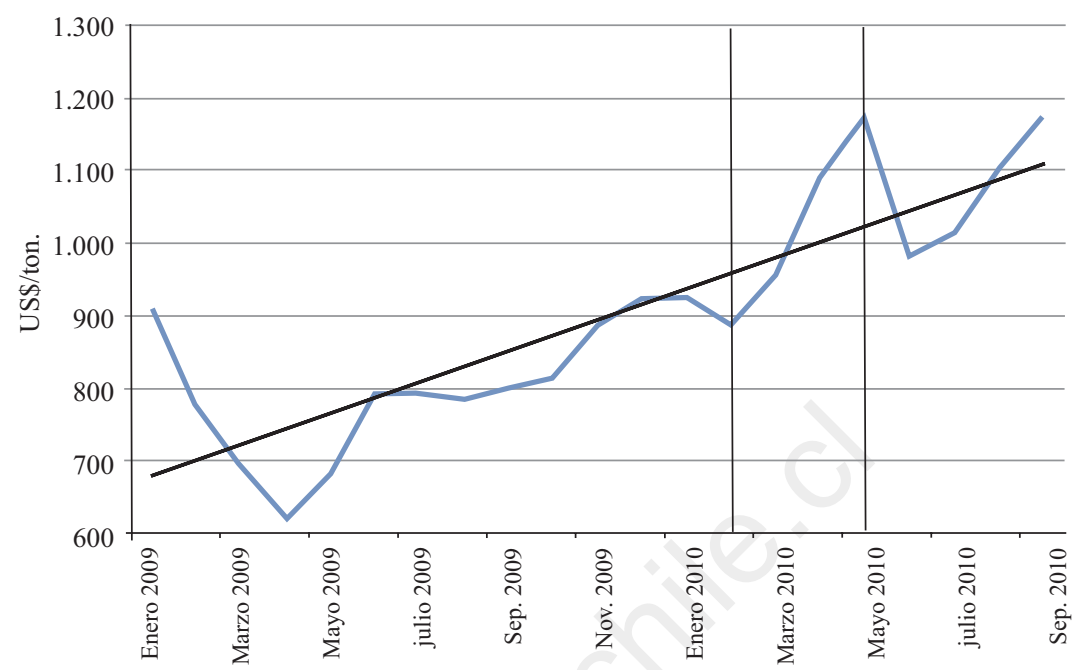

Fuente: Food and Agriculture Organization.

La Figura $\mathrm{N}^{\circ} 2$ muestra un efecto similar para el precio del aceite de pescado. Si bien se observa una fuerte tendencia al alza desde antes de febrero de 2010, en los tres meses posteriores al terremoto y mientras hubo incertidumbre respecto a la capacidad productiva de corto plazo de Chile este incremento se agudizó, siendo de $32 \%$ en sólo tres meses. Los pronunciados aumentos de precios observados son evidencia de que, más allá de la baja importancia que pudiera tener cada pesquera de Chile individualmente, conjuntamente los productores sí tendrían capacidad de afectar los precios internacionales ${ }^{7}$.

La demanda de aceite de pescado. Un elemento relevante a considerarse en el análisis es que Chile es un consumidor sumamente importante en este mercado y, por lo tanto, políticas o shocks que afectan el precio de los diversos tipos de aceite tienen un impacto relevante

${ }^{7}$ La relevancia del efecto del terremoto en los precios internacionales de harina y aceite de pescado fue destacada por numerosos analistas a nivel internacional, entre los que pueden mencionarse a The Financial Times, Magicvalley.com, The Information Centre of China Feed Industry Association, FAO, Merco.Press, The Fisheries Secretariat, Gerson Lehrman Group, y Ag Weekly. 
en productores locales, principalmente en la salmonicultura. Según los datos de The International Fishmeal and Fish Oil Organisation (IFFO) publicados en www.aqua.cl ${ }^{8}$ durante el año 2006, "el $87 \%$ del total del aceite mundial se consumió en la acuicultura y de ese volumen, 439 mil toneladas fueron consumidas sólo por la salmonicultura (salmones y truchas), lo que significa que hoy más del $56 \%$ del total del aceite de pescado usado en la acuicultura va hacia los salmónidos. Esta industria acuícola es el principal consumidor mundial de aceite de pescado, seguido muy atrás por los otros peces marinos de cultivo (bacalao y engorda de atún, por ejemplo), que participan con un 14\%".

Durante el año 2006, previo a la crisis del salmón, Chile era el mayor consumidor a nivel mundial de aceite de pescado, dado su intensivo uso en la industria en la salmonicultura. Según The International Fishmeal and Fish Oil Organisation (IFFO) e ISTA Mielke GmbH, Chile fue el mayor consumidor de aceite de pescado del mundo junto a Noruega, con un consumo de 185.200 toneladas durante el año 2006, representando su consumo el $19 \%$ de la producción mundial de aceite de pescado. Durante el año 2009 y no obstante los efectos de la crisis del salmón, Chile se encuentra en el segundo lugar después de Noruega como consumidor a nivel mundial de aceite de pescado, con un consumo de 113.700 toneladas, representando su consumo el $11 \%$ de la producción mundial de aceite de pescado.

\subsection{Concentración de mercado y cuotas de pesca en Chile}

Concentración de mercado. La Tabla $\mathrm{N}^{\circ} 1$ resume, en base a información del Instituto de Fomento Pesquero (IFOP), los principales productores de harina y de aceite de pescado para los años 2008 y 2009. Se aprecia que tanto la producción de harina de pescado como de aceite de pescado parecen a priori evidenciar coeficientes de concentración K3 (porcentaje de producción de las 3 principales empresas) relativamente bajos, con índices de Herfindahl-Hirschman (IHH) que indicarían entre baja y moderada concentración de mercado para ambos sectores de acuerdo a los criterios de la Fiscalía Nacional Económica. No obstante lo anterior, la concentración actual sería mayor a la presentada dadas las

8 "Estabilidad para la harina y aceite", por V. Mitrano, gerente general de Exapesca, Aqua, mayo 2007. 
TABLA N ${ }^{\circ}$ 1: $\quad$ PRODUCCIÓN DE HARINA Y ACEITE DE PESCADO EN CHILE (\% POR EMPRESA)

\begin{tabular}{|c|c|c|c|c|}
\hline \multirow[b]{2}{*}{ Empresa } & \multicolumn{2}{|c|}{ Harina de pescado } & \multicolumn{2}{|c|}{ Aceite de pescado } \\
\hline & 2008 & 2009 & 2008 & 2009 \\
\hline Corpesca & 26 & 22 & 14 & 14 \\
\hline Alimar & 12 & 13 & 14 & 13 \\
\hline Camanchaca & 14 & 13 & 8 & 12 \\
\hline Itata & 10 & 9 & 11 & 10 \\
\hline San José & 8 & 9 & 8 & 9 \\
\hline SPK & 6 & 7 & 13 & 8 \\
\hline El Golfo & 5 & 7 & 7 & 7 \\
\hline Foodcorp & $\mathrm{S}$ & S & 7 & 7 \\
\hline Bío Bío & 4 & 5 & 6 & 6 \\
\hline Lota Protein & 4 & 4 & 5 & 6 \\
\hline Landes & 3 & 4 & 5 & 5 \\
\hline Bahía Coronel & 2 & 2 & 3 & 3 \\
\hline Total & 100 & 100 & 100 & 100 \\
\hline Coef. de Concentración: K3 & 51 & 48 & 41 & 39 \\
\hline Coef. de Concentración: K3* & 73 & 72 & $67 \%$ & 65 \\
\hline Índice de Concentración: IHH & 1.305 & 1.169 & 989 & 958 \\
\hline Índice de Concentración: IHH* & 2.347 & 2.254 & 2.046 & 2.080 \\
\hline
\end{tabular}

*: K3 e IHH considerando la fusión de Corpesca, San José y SPK y los anuncios de fusión de Itata y El Golfo por un lado y Camanchaca y Bío Bío por otra.

Fuente: Elaboración propia en base a Instituto de Fomento Pesquero (IFOP).

recientes fusiones entre South Pacific Korp (SPK) y Pesquera San José y la anunciada en enero de 2011 entre Itata y El Golfo.

Al analizar la participación de estos grupos productivos en la producción de harinas de pescado, considerando un comportamiento conjunto de las empresas Corpesca, SPK y San José ${ }^{9}$, se puede observar que el sector evidencia un coeficiente de concentración K3 cercano al $70 \%$, con un IHH ligeramente superior a los 2.100 puntos, lo que indica un mercado altamente concentrado de acuerdo al criterio de la Fiscalía Nacional Económica (2006). En la producción nacional de aceite de pescado, los niveles de concentración son algo inferiores, pero en

${ }^{9}$ Corpesca pertenece al mismo grupo económico que SPK - grupo Angelini- que, en definitiva, tendrá el control de la empresa fusionada con el $60 \%$ de las acciones. 
cualquier caso se trata de una actividad altamente concentrada a nivel nacional.

Adicionalmente, las principales empresas del sector han conformado sociedades con fines específicos para apoyo de sus actividades, formalizando el trabajo conjunto en distintas áreas de interés ${ }^{10}$. Una de las más importantes es, sin duda, Exapesca S.A. creada por dieciséis empresas en 1994 con el objeto de comercializar el aceite de pescado. En la actualidad, según consta en su propia página web www.exapesca.cl se encuentra conformada por Pesquera San José S.A., Pesquera Bío Bío S.A., Soc. Pesquera Landes S.A., Pesquera Bahía Coronel S.A. y Alimar S.A., que producen alrededor del $50 \%$ del aceite de pescado del Sur de Chile $^{11}$.

Transacciones de cuotas. De acuerdo a la normativa vigente las cuotas de pesca están en la actualidad ligadas a las embarcaciones y, por lo tanto, la transferencia de una implicaría necesariamente la transferencia de la nave. En la práctica, sin embargo, esto no es necesariamente así puesto que la empresa que vende la cuota (y potencialmente la nave) puede firmar un contrato con un armador y asignar la cuota que se desea vender a la nueva nave "en construcción", de manera que el comprador adquiere la cuota y el contrato con el armador por la construcción de la nueva nave y utiliza la cuota con una embarcación propia (real), mientras se construye la nueva embarcación lo que, en definitiva, no ocurrirá.

La Figura $\mathrm{N}^{\circ} 3$, reproducción del gráfico de la Proposición $\mathrm{N}^{\circ} 12$ del TDLC, ilustra la evolución de las cantidades de naves transferidas entre 2002 y 2009 que significaron un cambio efectivo de propiedad para el total de pesquerías sujetas al régimen de cuotas individuales y para las del jurel, anchoveta y sardina común. La gran cantidad de transacciones observadas en los primeros años desde 2001 podría llevar a la conclusión errónea de que no existen barreras de entrada a este mer-

10 "Club de la pesca o licitaciones competitivas". Presentación de M. Cruzat al TDLC, agosto 2010.

${ }^{11}$ Otras empresas conformadas con diferentes fines específicos y por diferentes grupos son Boat Parking S.A. (destinada a otorgar servicio de estacionamiento en tierra y mantención de naves), Emisario Coronel S.A. (destinada a construir y operar un colector común para los residuos industriales) y Cannex S.A. (con el objeto de producir, distribuir y vender productos del mar enlatados y congelados para consumo humano). 
FIGURA N ${ }^{\circ}$ 3: $\quad$ NÚMERO TOTAL DE TRANSFERENCIAS DE NAVES CON PERMISOS DE PESCA SUJETAS A LMCA

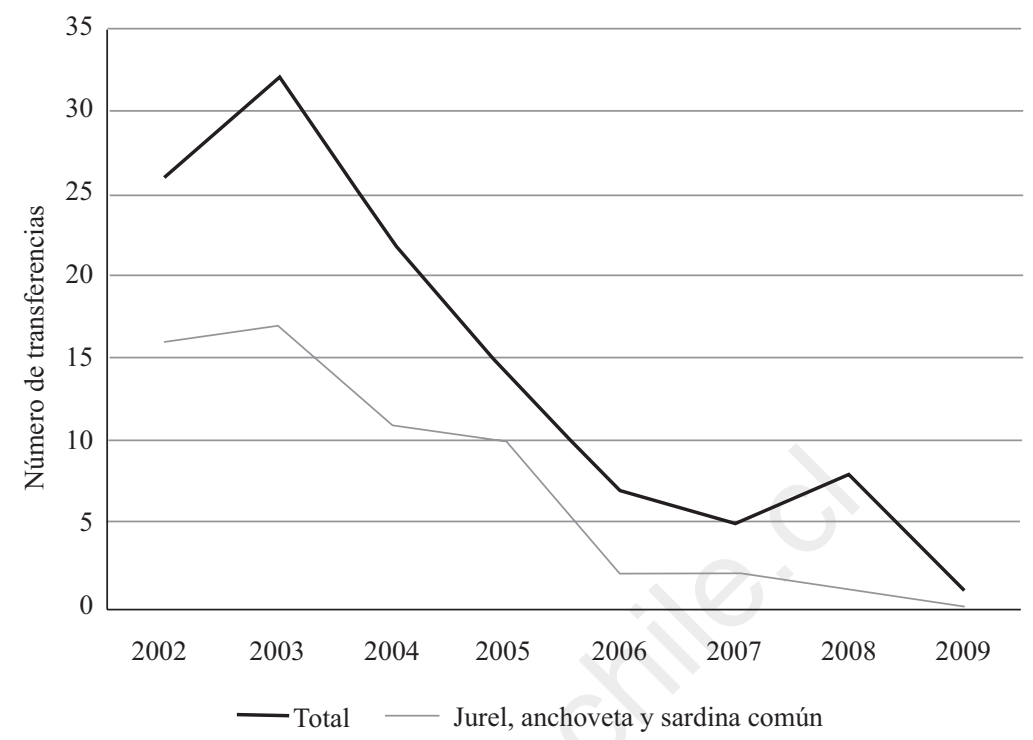

Fuente: Proposición № 12, TDLC (2011).

cado. No obstante, al analizar el listado con la evolución de los barcos pesqueros por empresa, desde el año 2001 a la fecha (véase anexo II de la Consulta de Lota Protein), se puede observar la existencia de sólo 3 empresas diferentes a las originalmente presentes en el mercado en el año 2001: SPK, San José y Foodcorp. Sin embargo, estas tres empresas son controladas o están relacionadas con empresas originalmente presentes en el año 2001: SPK es controlada por Pesquera IquiqueGuanaye, empresa originalmente presente en el año 2001, San José es controlada por Coloso, también presente en el año 2001 y finalmente Foodcorp Chile es la antigua empresa Pacific Fisheries. Por lo tanto, desde el año 2001 no han ingresados nuevas empresas a este mercado.

De acuerdo al análisis del TDLC, la evidencia ilustrada en el gráfico anterior no permite concluir si ésta corresponde a un mercado que funciona eficientemente y a través de los años encuentra su equilibrio de largo plazo, o es consecuencia de distorsiones en el funcionamiento del mismo. Considera sí que un factor que puede explicar al menos parcialmente la merma en el número de transacciones es la mayor incertidumbre respecto al valor de las cuotas a medida que se acerca su expiración en 2012 y no haya certeza respecto al proceso de reasignación. Esta posible afirmación al menos es contradicha por Villena, Niño y 
Zechetti (2010), quienes argumentan que el número de transacciones de los últimos años es inferior al número de transacciones óptimo. En otras palabras, estos autores se inclinan por la primera explicación ${ }^{12}$.

No obstante, como resultado de las recientes fusiones y de las transacciones de cuotas observadas, el mercado de cuotas para las pesquerías de la zona Centro-Sur de Chile se encuentra altamente concentrado, tal como refleja la Tabla $\mathrm{N}^{\circ} 2$.

TABLA N ${ }^{\circ}$ 2: $\quad$ TENENCIAS DE CUOTAS EN PESQUERÍAS ZONA CENTRO-SUR

Empresa $\quad$ \% cuota 2009

$\begin{array}{lr}\text { Alimar } & 13,4 \\ \text { SPK - San José } & 21,5 \\ \text { Itata - El Golfo } & 23,9 \\ \text { Camanchaca - Bío Bío } & 18,9 \\ \text { Foodcorp } & 8,3 \\ \text { Landes } & 5,5 \\ \text { Nacional } & 5,0 \\ \text { Lota Protein } & 1,8 \\ \text { Otros } & 1,7 \\ & \\ \text { Total } & 100\end{array}$

Fuente: Elaboración propia en base a Montero (2010).

El bajo número de actores en este mercado de cuotas y el bajo número de transacciones observadas especialmente en los últimos años lleva a pensar que estas transacciones son fruto de negociaciones bilaterales entre empresas, más que de decisiones tomadas en el seno de un mercado líquido por estos activos. Esta hipótesis tiene sustento teórico y empírico en la literatura de finanzas corporativas (Holmström y Tirole, 1993; Tirole, 2006, capítulo 8). Desde el plano teórico son dos los enfoques que sustentan nuestra hipótesis, el de selección adversa y el de transacciones. El enfoque de selección adversa plantea que cuando los propietarios que están presentes en la industria poseen información superior a la de quienes están fuera de la industria, se produce una asi-

${ }^{12}$ Los autores muestran que mientras el año 2008 se transó el 1\% de la cuota global en la región centro-sur de Chile, sus estimaciones revelan que el número óptimo de transacciones debería haber sido del $9 \%$ de la cuota global. En otras palabras, la diferencia es de orden de magnitud significativa. 
metría de información que reduce la liquidez de los activos (Grossman y Stiglitz, 1980; Glosten y Milgrom, 1985; Easley y O'Hara, 1987). Adicionalmente, el enfoque de transacciones sostiene que un mercado concentrado tiene elevados costos de transacción, lo que reduce su liquidez (Demsetz, 1968; Merton, 1987).

La evidencia empírica muestra que en tanto sean los inversionistas presentes en la industria quienes estén más informados que los externos, las predicciones de ambos enfoques apuntan en la misma dirección. Esto es, a mayor concentración de la propiedad en los mismos inversionistas, menor liquidez en el mercado. Evidencia de que las asimetrías de información producen pocas transacciones en el mercado son los trabajos de Jaffe (1974), Lin y Howe (1990); Bettis, Coles y Lemmon (2000), Lakonishok y Lee (2001) y Rubin (2007).

En definitiva, la alta concentración en esta industria y las pocas transacciones de cuotas de pesca en los años recientes podrían ser explicadas por la existencia de asimetrías de información y la alta concentración, la que a su vez refuerza la existencia de asimetrías que nacen precisamente de esta alta concentración en los mismos pocos inversionistas.

\subsection{La integración vertical hacia el sector acuícola}

Un cuarto aspecto saliente de la evolución del sector en los últimos años es la creciente integración vertical con el sector de la acuicultura. Si bien la existencia de empresas provenientes del sector pesquero industrial en la acuicultura es de larga data, a partir de los años 2005 y 2006 se han ido paulatinamente incorporando cada vez más actores del sector de la pesca industrial, motivados posiblemente por las ventajas originadas en la integración "hacia abajo", ya que la harina y aceite de pescado constituyen un insumo básico de la acuicultura. La Tabla $\mathrm{N}^{\circ} 3$ resume la información respecto a las principales pesqueras que participan también en el sector de la salmonicultura y desde cuándo lo hacen.

Las razones para la creciente participación de los pescadores industriales en el sector acuícola no son en absoluto evidentes, pues no existen economías de ámbito relevantes en la producción de harina y aceite de pescado y la cría y comercialización de salmones. El TDLC en su Proposición $\mathrm{N}^{\mathrm{o}} 12$ analiza la posibilidad que esta creciente integración estuviera relacionada con prácticas contrarias a la libre competencia, pero finalmente concluye que no existen suficientes elementos para formarse convicción en tal sentido. 
TABLA N ${ }^{\circ}$ 3: $\quad$ PESQUERAS INDUSTRIALES RELACIONADAS A LA SALMONICULTURA

\begin{tabular}{lccc}
\hline Empresa pesquera & Empresa salmonera & Año de inicio & \% exportaciones totales \\
\hline Camanchaca & Camanchaca & 1986 & 6,48 \\
El Golfo & El Golfo & 2005 & 1,48 \\
Landes & Landes & 2009 & 0,00 \\
Bahía Coronel & Salmones Chile & 1986 & 0,90 \\
Friosur & Friosur & 1986 & 2,66 \\
Coloso & Humboldt - San José & 2006 & 0,88 \\
Bío Bío & Congelados Pacífico & 2009 & n.d. \\
Itata & Itata & 2006 & 2,15 \\
Total & & & 14,55 \\
\hline
\end{tabular}

Fuente: Elaboración propia en base a TDLC (2011), información de empresas y artículos periodísticos.

\section{El mercado de cuotas de pesca y el potencial rol de las subastas}

\section{A. El teorema de Coase y el rol de los costos de transacción}

Ronald Coase ha sido sin dudas uno de los economistas más relevantes del siglo XX. Entre sus trabajos más importantes se encuentran "The Nature of the Firm" de 1937 y "The Problem of Social Cost", publicado en 1960. En el primero de ellos Coase pone de manifiesto la importancia que pueden tener en la decisión de estructurar una firma y definir su tamaño los costos de utilizar el mercado como medio para procurar determinados bienes o servicios. Simplificando el argumento, si los costos de transacción para obtener un determinado bien en el mercado son mayores que los de producirlo al interior de la misma, entonces la firma optará por producirlo internamente.

En su trabajo de 1960, la noción de costos de transacción también es central a los argumentos expuestos. Coase generaliza argumentos presentados en un artículo anterior (Coase, 1959) y da forma a lo que años después Stigler (1989) bautizaría como el "teorema de Coase". Informalmente explicada su hipótesis de eficiencia, este teorema dice que en ausencia de costos de transacción, el cómo se asignen derechos de propiedad es irrelevante para la determinación del uso que se dará a los activos y, más aún, este uso será siempre el socialmente eficiente. Es decir que su implicancia es doble: no sólo que la asignación inicial es irrelevante para el resultado, sino que también el resultado es necesariamente eficiente. 
Si bien en muchos casos este teorema ha sido utilizado y ejemplificado con situaciones en que una parte genera externalidades a la otra, el resultado es más general y su lógica es válida para cualquier intercambio económico ${ }^{13}$. En términos de la consulta realizada al TDLC respecto a la asignación inicial de cuotas de pesca sus implicancias serían evidentes: si fuera posible transar sin costos las cuotas de pesca, no importaría cómo se asignen inicialmente ya que las partes interesadas transarán hasta llegar a una asignación eficiente; quienes más valoren las cuotas comprarán a quienes las valoran menos. Con esta lógica por detrás, la recomendación obvia es hacer todo lo posible para reducir los costos de transar cuotas. Entre las recomendaciones más evidentes (e importantes) se incluye la de separar la propiedad de la cuota de la propiedad de las naves, lo que no sólo facilitaría la transferencia definitiva de cuotas sino que también podría ayudar a generar un mercado de arriendos de corto plazo de las mismas.

Sin embargo, los costos de transacción existen, Coase plantea:

El argumento hasta aquí se ha hecho bajo el supuesto que no hay costos involucrados por llevar adelante transacciones en el mercado. Este es, sin duda, un supuesto muy irreal. Para llevar adelante una transacción en el mercado es necesario descubrir con quién se quiere transar, informarle en qué términos se desea transar, llevar adelante negociaciones, escribir el contrato, realizar las inspecciones necesarias para asegurarse que los términos del contrato se están cumpliendo, etc. Estas operaciones son a menudo extremadamente costosas, lo suficiente para evitar que se concreten muchas transacciones que se llevarían adelante en un mundo en que el sistema de precios funcionara $\sin \operatorname{costos}^{14}$.

Desde un punto de vista lógico, la existencia de costos de transacción en la realidad no invalida al teorema de Coase puesto que es un supuesto del teorema que estos no existen. Por el contrario, el teorema

${ }^{13}$ En el clásico ejemplo del ranchero cuyas vacas arruinan el cultivo del vecino, suponiendo que el ranchero tiene derecho a dejar libres las vacas y lo socialmente eficiente es que esto no ocurra, la negociación entre el ranchero y el agricultor llevará a que el ranchero impida que sus vacas arruinen el cultivo; hecho que puede pensarse como la transacción de un derecho (el derecho a que las vacas "circulen libremente") del ranchero a favor del agricultor.

14 Traducción de los autores de Coase (1960), de la versión reimpresa en Coase (1988), p. 114. 
ha sido muy influyente, en particular en el área de Derecho y Economía, porque en la realidad sí existen costos de transacción. Luego, es esperable que muchas transacciones que serían eficientes no ocurran por la existencia de costos de transacción, por lo que se torna absolutamente relevante la asignación inicial de los derechos que se haga. Por supuesto, esto es algo que Coase entiende perfectamente y así lo explicita:

El mundo con costos de transacción cero es a menudo descrito como el mundo de Coase. Nada podría estar más alejado de la realidad. Este es el mundo de la teoría económica moderna; mundo que yo esperaba convencer a los economistas que abandonaran ${ }^{15}$.

Efectivamente, el objetivo de Coase era, mostrando que en un mundo sin costos de transacción la institucionalidad sería irrelevante, cambiar el foco de análisis desde un mundo sin costos de transacción - supuesto que ha sido utilizado en el desarrollo de la microeconomía clásica- a uno real con costos positivos de transacción. En este mundo real se torna fundamental el estudio no sólo de las transacciones en el mercado y sus costos asociados, sino también y por lo mismo de la institucionalidad que sustenta la producción y el intercambio y genera las asignaciones iniciales de derechos.

Su éxito, en el sentido de cambiar el foco de estudio fue sólo parcial ya que si bien su trabajo afectó enormemente en el área de Derecho y Economía, el área de lo que se ha llamado "Economía de los Costos de Transacción" es de una importancia cuantitativa relativamente menor en la ciencia económica. De acuerdo al propio Coase:

El Problema del Costo Social [...] ha sido ampliamente citado y discutido en la literatura económica. Pero su influencia en el análisis económico ha sido menos beneficiosa de lo que esperaba. La discusión se ha concentrado en las secciones III y IV del artículo, en particular en lo que se conoce como el "teorema de Coase", descuidándose otros aspectos del análisis. En las secciones III y IV examinaba qué pasaría en un mundo en que los costos de transacción se suponían iguales a cero. Mi objetivo al hacerlo no era describir cómo sería la vida en un mundo como ese, sino proveer un marco simple para desarrollar el análisis y, lo que es más importante, hacer

${ }^{15}$ Ibídem, p. 174. 
patente el rol que los costos de transacción tienen, y deberían tener, en el diseño de las instituciones que conforman el sistema económico ${ }^{16}$.

Volviendo al problema de las cuotas individuales de pesca, es evidente que debieran tomarse todas las medidas para reducir los costos de transacción. Lo debatible y controversial es qué hacer en un mundo en que los costos de transacción pueden reducirse pero no eliminarse completamente. Retomando la última cita de Coase, su teorema nada dice respecto al hecho de que en circunstancias en que los costos de transacción existen, determinadas acciones del gobierno pueden (o no) proveer soluciones mejores que las que generaría una negociación entre las partes. Y como bien señala Coase, las diferentes opciones de políticas —v.g., asignación de cuotas de acuerdo a criterios históricos o a través de una subasta- deberían compararse no en el contexto de un mundo irreal (e ideal) sin costos de transacción, sino considerando las instituciones y los gobiernos que se tienen y los posibles costos de transacción existentes.

En el contexto de la asignación inicial de las cuotas individuales de pesca, es correcto insistir en que se debiera legislar de modo que el mercado funcione lo mejor posible, con los menores costos de transacción para mejorar la eficiencia del mercado. Aun cuando no se eliminen completamente los costos de transacción, tener menos costos es mejor que tener más costos de transacción. No es blanco o negro. La pregunta relevante es, como ya se dijo, si puede confiarse solamente en la reducción de los costos de transacción o si puede hacerse algo más en aras de la eficiencia.

¿Qué más podría hacerse en aras de la eficiencia? La respuesta obvia es intentar una asignación inicial que sea socialmente eficiente en un contexto en que quien debe asignarlas desconoce quiénes son los actores más eficientes. En estas circunstancias, los mecanismos más útiles que conocemos los economistas son los distintos tipos de subastas.

En consecuencia, para concluir este análisis basado solamente en costos de transacción, para enviar su proyecto de Ley el Poder Ejecutivo debería analizar los costos y beneficios esperados de dos opciones:

${ }^{16}$ Ibídem, p. 13. 
1. Tómese el paquete de medidas X que permitirán reducir los costos de transacción y asígnense las cuotas de acuerdo a criterio histórico.

2. Tómese el paquete de medidas $X^{\prime}$ que permitirán reducir los costos de transacción y organícese una subasta para la asignación de las cuotas iniciales.

A favor de la opción 1 está el hecho de que es innecesario organizar una subasta, la que conlleva costos mayores que una asignación directa a partir de información disponible. A favor de la opción 2 está el que el paquete de medidas $\mathrm{X}$ que finalmente apruebe el Congreso (bien podría ocurrir que $\mathrm{X}$ sea diferente de $\mathrm{X}^{\prime}$ ) reduzca los costos de transacción, pero no lo suficiente y que, por lo tanto, la asignación resultante ex post sea socialmente menos eficiente que la que arrojaría la subasta.

La comparación anterior depende entonces de los costos de organizar una subasta y de la efectividad esperada del paquete de medidas para reducir los costos de transacción. Esta efectividad esperada, vale la pena recalcarlo, no es la de un paquete de "medidas ideales" que aprobaría un "Congreso ideal" y serían aplicadas en un "país ideal"", sino lo que razonablemente podría esperarse que el Congreso aprobase y cómo ello funcionaría en un mercado relativamente pequeño, con pocos actores, en el que la cantidad total a extraerse del recurso es fijada por un organismo colegiado en el que participan los mismos pescadores industriales, el gobierno e instancias técnicas, y en el que los industriales se han integrado verticalmente a la etapa de procesamiento de harina, aceite y congelados y, crecientemente en los últimos años, a la industria del salmón que utiliza los primeros como insumos básicos.

\subsection{Myerson-Satterthwaite y las asimetrías de información}

El teorema de Coase fue formulado en los años 60, época en la que recién empezaban a surgir los análisis de los mercados en contextos de asimetrías de información. Estos parten con los trabajos seminales de William Vickrey en el contexto de subastas y, ya con mucha más fuerza

${ }^{17}$ Realizar la comparación de las opciones en un mundo sin costos de transacción sería irrelevante; ambas opciones serían igualmente buenas y sin costos. 
en los años 70, con los trabajos de George Akerlof, George Mirrlees, Michael Spence, Joseph Stiglitz y el propio Roger Myerson (todos ellos ganadores del premio Nobel de Economía). El teorema de Coase no se hace cargo de las asimetrías de información; es más, en Coase (1960) la palabra information no es mencionada. En la extensa discusión que hace en ese artículo del ejemplo del ranchero y el agricultor no hay una mención explícita respecto a si estos dos individuos son ignorantes de los costos de mitigar el daño que hacían las vacas y/o del costo en términos de producción para el agricultor ${ }^{18}$.

El teorema de Coase es correcto sólo si se consideran escenarios de información completa, es decir donde cada parte conoce exactamente "los pagos" de la otra, es decir sus costos, ingresos, etc. O, lo que es equivalente, si se interpreta la existencia de asimetrías de información como un costo de transacción, entonces no se cumpliría el supuesto del teorema de que estos son iguales a cero y, por lo tanto, su conclusión respecto a la eficiencia de la asignación final independientemente de la asignación inicial ${ }^{19}$.

La existencia de asimetrías de información entre las partes que negocian puede llevar a que el resultado de la negociación sea ineficiente y, por lo tanto, la asignación inicial de derechos sea absolutamente relevante. Este resultado fue formalmente demostrado hace tres décadas y se conoce como el teorema de Myerson-Satterthwaite (1983).

Entonces, o bien el teorema de Coase es falso o en la definición implícita de costos de transacción agregamos la existencia de asimetrías de información, en cuyo caso podemos afirmar que es casi tautológico: al descubrir circunstancias en las que fallaría llamamos a esas circunstancias "costos de transacción".

18 Para algunos autores (véase, por ejemplo McKelvey y Page, 2000, nota a pie 1), si bien Coase no es explícito al respecto, la intención era que la aplicabilidad del teorema fuera válida para contextos con asimetrías de información ya que no hizo explícita una restricción a contextos de información completa y, adicionalmente, muchos de los ejemplos discutidos corresponden a casos en que el supuesto natural es de información privada.

${ }^{19}$ En definitiva, es irrelevante si consideramos a las asimetrías de información como costos de transacción y por lo tanto el teorema sería correcto; o si consideramos que el teorema es incorrecto (o sólo correcto en la medida que no existan costos de transacción). Lo relevante es que cuando existen asimetrías de información entre quienes deberían negociar en el mercado, aun cuando no hubiera otros costos de transacción, la negociación podría llevar a resultados ineficientes $\mathrm{y}$, por lo mismo, la asignación inicial de derechos es relevante. 
El teorema de Myerson-Satterthwaite informalmente enunciado dice: Si el vendedor de un objeto lo valora en algún monto v' que él conoce (este monto puede interpretarse también como el costo de producir el bien) y que el comprador desconoce pero sabe que es algún valor en el intervalo $[\mathrm{v}, \mathrm{V}]$; y si el comprador valora el objeto en un monto c' que él conoce y que el vendedor desconoce pero sabe que es algún valor en el intervalo $[\mathrm{c}, \mathrm{C}]$ y se cumple que $\mathrm{V}>\mathrm{c}$; entonces no existe proceso de negociación (ni otro "mecanismo") que garantice que siempre que c' sea mayor que v' las partes lleguen a un acuerdo y la transacción se realice. Es decir, no hay manera de garantizar que cuando es eficiente que la transacción se realice ( $c^{\prime}>v^{\prime}$ ), esta efectivamente se realice.

La intuición de este resultado es relativamente simple. Tanto el comprador como el vendedor carecen de incentivos para revelar su verdadera valoración por el objeto. El primero querrá impostar una valoración menor (procurando de este modo que el precio sea más bajo) y el segundo una valoración mayor (procurando que el precio sea más alto). Por ejemplo, si se piensa en una negociación estructurada de modo que el comprador realiza una oferta "tómalo o déjalo" ${ }^{20}$, el vendedor tendría incentivo a aceptar la oferta cuando ésta sea igual o mayor a v', pero el comprador tendría incentivo a ofrecer un monto inferior a c'. La razón es obvia, si ofrece c' obtendría una ganancia neta de cero, se realice o no la transacción, mientras que si ofrece menos con probabilidad positiva obtiene un excedente positivo.

Un análisis análogo puede realizarse invirtiendo los roles de quién realiza la oferta y quién puede sólo aceptar o rechazar. Pero el teorema de Myerson-Satterthwaite es mucho más general, ya que demuestra que no existe ningún mecanismo que las partes podrían idear que garantice la eficiencia (es decir, que haya transacción siempre que c' $\left.>v^{\prime}\right)^{21}$.

${ }^{20}$ Esto es, que el vendedor puede rechazar, en cuyo caso no habría transacción; o aceptar, en cuyo caso la transacción se concreta al precio ofertado.

${ }^{21}$ Formalmente, dice que no existe mecanismo alguno que sea un incentivo compatible (es decir, que induzca a las partes a revelar verdaderamente su información privada), satisfaga las restricciones de participación interinas (es decir, aquellas que deben satisfacerse una vez que las partes conocen su valoración) e induzca la transacción siempre que ello sea eficiente. Para una demostración y enunciación formal del teorema puede consultarse Fudenberg y Tirole (1991), pp. 275-279. Los "mecanismos" pueden en principio ser procesos muy complejos, con sucesivas rondas en que las partes se envían "mensajes" como podrían ser ofertas y contraofertas, rechazos y aceptaciones de éstas, etc. y, ciertamente, incluyen procesos dinámicos en que, a priori pero erradamente, podría pensarse que las partes debieran ser capaces de dilucidar la valoración del rival. 
Es importante precisar a qué se refiere la existencia de información asimétrica. Es frecuente creer que las asimetrías de información se refieren necesariamente a que las características del objeto no estuvieran claramente definidas o que una de las partes conoce el objeto mejor que la otra. Esto es incorrecto (o al menos impreciso). La asimetría de información relevante en términos del teorema se refiere simplemente a que cada parte desconoce la valoración exacta del bien para la otra parte.

Este desconocimiento podría provenir obviamente de un conocimiento asimétrico del objeto transado. Por ejemplo, en el caso que nos ocupa, si la cuota está asociada a la embarcación es razonable pensar que el vendedor tenga una mejor estimación de su valor real. Pero ello no es en absoluto necesario y, por lo tanto, no se remedia necesariamente eliminando la asociación entre cuota y embarcación. La mera heterogeneidad de las funciones de producción, por ejemplo, ya genera asimetrías de información respecto de la valoración de la cuota de uno y otro (a menos que se suponga que cada parte conoce exactamente la función de costos del proceso de captura del otro y de sus posteriores fases de elaboración). El tiempo que lleven los distintos actores en el mercado puede generar que uno conozca mejor que el otro la dinámica del recurso explotado, o que tenga mayor injerencia en la fijación de la cuota global y, por lo tanto, una noción más precisa del valor actual de la cuota.

Otras fuentes de asimetrías de información se derivan también del hecho que los incumbents se hallan integrados con las etapas de procesamiento de los pescados, tienen mejor información, por ejemplo, respecto a la eficacia del regulador en el control de los desembarques y otros aspectos relacionados a las faenas de pesca, tienen representación ante los órganos regionales de pesca, etc.

Si bien la versión original del teorema de Myerson-Satterthwaite fue enunciada para el caso de una transacción entre dos partes y un bien indivisible, o de un bien divisible e individuos con funciones de utilidad cuasilineales, posteriormente diferentes autores han demostrado que el resultado es válido en contextos más generales (véase Cramton, Gibbons y Klemperer, 1987 y, más recientemente, McKelvey y Page, 2002).

En un artículo relacionado, McKelvey y Page (2000) realizan un experimento bajo condiciones de información completa y de información privada, encontrando que el efecto de información privada es 
altamente relevante, en el sentido que en muchas ocasiones las negociaciones entre los sujetos del experimento llevan a resultados ineficientes y que, además, la asignación inicial del bien (entendida como la asignación que resultará en caso que la negociación falle, o disagreement point de la negociación) es relevante. Ambos resultados indican que la evidencia empírica es más consistente con las condiciones del teorema de Myerson-Satterthwaite que con las del de Coase. El sesgo que se genera en la negociación bajo información imperfecta es hacia el status quo, es decir a que haya menos transacciones de las eficientes y/o a que, en el caso de bienes divisibles, el propietario original del bien retenga una porción del mismo mayor que la eficiente.

En definitiva, la aplicabilidad del teorema de Coase, como se argumentó, es restringida en general dada la omnipresencia de los costos de transacción, y simplemente incorrecta en contextos en que existen asimetrías de información. Por lo tanto, aun cuando las ventajas de información que pueden tener los pescadores ya establecidos no provinieran de comportamientos contrarios a la libre competencia, no menos cierto es que, si existieran asimetrías de información, sería temerario sugerir que la asignación inicial de las cuotas que realice el legislador es irrelevante desde el punto de vista de la eficiencia económica.

\subsection{El rol de las subastas y el diseño de mecanismos}

Las subastas tienen por objetivo primordial generar competencia ex ante en mercados en donde por razones varias no es posible más competencia ex post. Las subastas son superiores a otros mecanismos (v. g., la contratación directa) en contextos en que existen asimetrías de información entre el subastador y los potenciales participantes respecto a la valoración de estos por el objeto. En el caso de la asignación de cuotas individuales de pesca, administrativamente el Estado determina que no es posible la entrada a la extracción de peces, salvo que se cuente con alguna cuota asignada. A este rol primordial de las subastas se le pueden sumar una serie de objetivos subsidiarios; a saber, promover la entrada eficiente en la industria, reducir la incertidumbre, generar información relevante para el mercado en cuestión, evitar la colusión, etc.

No existe el mecanismo o subasta ideal que cumpla con todos los objetivos subsidiarios de forma consistente, existiendo muchas veces soluciones que consideran algunos aspectos teóricos con la experiencia 
práctica y los problemas de viabilidad de lo que se infiera de la teoría. La experiencia internacional en el diseño de subastas muestra que los temas centrales de la organización industrial — como son la existencia de barreras a la entrada, la colusión o la predación - son los que dominan los criterios para diseñar el mecanismo de la subasta, dando cuentas estos del primer objetivo subsidiario ${ }^{22}$.

Puede jugar además un rol importante en el diseño de subastas la racionalidad limitada que en la práctica tienen los oferentes, lo que es particularmente relevante en subastas de múltiples objetos con complementariedades entre los mismos (v.g., subastas del derecho de uso del espectro radioeléctrico en múltiples localidades). Consideraciones de este tipo llevan a los subastadores muchas veces a diseñar subastas más simples de lo que la teoría indicaría.

Un problema asociado al de la racionalidad limitada de los participantes es la famosa "maldición del ganador", según la cual quien resulta ganador del objeto subastado podría terminar pagando más de lo que el objeto vale. Este fenómeno puede darse en contextos de subastas de objetos cuyo valor incierto tiene un importante componente común a todos los oferentes (como sería ciertamente en el caso de las cuotas de pesca la incertidumbre respecto al precio del recurso), y se daría en la medida que los oferentes calculan el valor esperado del objeto en base a la información que poseen pero fallan en calcular el valor esperado del objeto subastado condicional en el hecho de ganar la subasta. De esta manera, quien resulta ganador puede serlo porque ha sido el más optimista respecto a la variable de incertidumbre y puede, por lo tanto, pagar más de lo que el objeto vale en realidad.

Respecto a la relevancia práctica de este potencial problema, vale la pena considerar varios aspectos. En primer lugar, no es infrecuente (particularmente en contextos de subastas organizadas por un organismo del Estado) que la invocación del problema de la maldición del ganador sea un argumento utilizado para buscar renegociar los términos de un contrato. La maldición del ganador puede ocurrir entre participantes inexpertos, pero no debería ocurrir entre oferentes sofisticados

${ }^{22}$ Referencias obligadas en este tópico son Krishna (2002), Klemperer (2004), Milgrom (2004). En materia de aplicaciones del diseño de subastas, se puede consultar el propio trabajo de Klemperer (2004), así como McAffee (1998) para temas relacionados a privatizaciones y concesiones, y McMillan (1994) para subastas en telecomunicaciones. 
y/o correctamente asesorados. Por otra parte, aun cuando efectivamente ocurriera la maldición del ganador, sus consecuencias en términos de eficiencia pueden ser nulas. En efecto, si todos los participantes fueran "no sofisticados" — en el sentido de no prever este fenómeno-, de igual modo ganaría la subasta quien asigna el mayor valor esperado al objeto (aun cuando calcule mal este valor esperado), y por lo tanto la asignación sería eficiente. Finalmente, vale la pena mencionar que si la maldición del ganador fuera una preocupación real para las autoridades, es posible diseñar la subasta de manera tal de minimizar este riesgo. Ello se logra, por ejemplo, mediante formatos de subastas como la inglesa en que el mismo proceso de la subasta va revelando información respecto a las valoraciones de otros postulantes ${ }^{23}$.

Una subasta cumple con el rol social de generar competencia en un mercado en donde esta no existe. Esto es válido siempre que en el momento de su diseño e implementación se tengan presentes al menos cuatro criterios que deben balancearse cuidadosamente: i) diseñar esquemas de subastas cuyos "equilibrios" sean en efecto eficientes, en el sentido de asignar las cuotas individuales de pesca a quienes más las valoran, lo que debería relacionarse con empresas más eficientes en su producción; ii) diseñar esquemas que promuevan la participación del mayor número posible de actores; iii) que dificulte la colusión entre los participantes; y iv) que la subasta sea relativamente simple, de manera de evitar que sus complejidades terminen afectando los criterios previos.

Es importante enfatizar por qué el resultado de una subasta puede ser eficiente y ello no es contradictorio con el teorema de MyersonSatterthwaite que enunciamos como "...no existe proceso alguno de negociación (ni otro "mecanismo") que garantice que siempre que c' sea mayor que v' las partes lleguen a un acuerdo y la transacción se realice..." La razón por la cual la subasta de las cuotas de pesca puede ser eficiente es que se introduce un actor, el Estado, que será el subastador/vendedor cuya valoración es siempre inferior a la de los potenciales compradores. En términos del teorema de MyersonSatterthwaite, al introducirse este subastador/vendedor el supuesto de "soporte común" de las valoraciones de comprador y vendedor (es

${ }^{23}$ Este tipo de subasta no es ajena al sector de la pesca en Chile (PeñaTorres y Fernández, 2010). 
decir, que la máxima valoración posible del vendedor sea mayor que la mínima del comprador) es inválido y, por lo tanto, el resultado de la subasta debería ser eficiente.

Naturalmente, las subastas no son infalibles y, por lo tanto, debe insistirse que el diseño de las mismas es fundamental para tener resultados exitosos y prevenir potenciales prácticas contrarias a la libre competencia, como sería la colusión o bid rigging, predación o exclusión de nuevos entrantes, o una mayor concentración en la industria. Una ventaja de la subasta como mecanismo de competencia ex ante radica en la posibilidad de considerar y mitigar explícitamente estos riesgos. A modo de ejemplo, y sin entrar a dictar pauta de cómo debe diseñarse la subasta de estas cuotas, este diseño puede reducir los riesgos de colusión por la vía de licitar menos cuotas que participantes, favorecer la simultaneidad en lugar de la secuencialidad en subastas de múltiples cuotas, etc. ${ }^{24}$ Igualmente, se pueden reducir los riesgos de mayor concentración por la simple vía de imponer restricciones al número total de cuotas o participaciones de mercado, como se hizo en las licitaciones de concesiones de tramos de la ruta 5 en Chile en el año 1997.

En conclusión, la gran ventaja de asignar las cuotas individuales de pesca usando el mecanismo de subastas es que con ello se emulan las condiciones de competencia, se corrigen o mitigan los potenciales problemas de organización industrial que pueda mostrar esta industria una vez en operación y, en definitiva, se terminan asignando los objetos subastados a quienes tienen una mayor valoración por los mismos. Dados los problemas de costos de transacción y asimetrías de información que limitan las transacciones posteriores, una asignación inicial eficiente (que sólo por casualidad podría lograrse por la vía administrativa) resulta fundamental para obtener una asignación final más eficiente.

\section{Reflexiones de política}

De manera sintética, el argumento que presentamos para preferir la asignación de las cuotas individuales de pesca mediante una subasta versus su asignación administrativa por criterios históricos es el siguien-

${ }^{24}$ Harrison (2010) entrega una propuesta concreta de un mecanismo de licitación de cuotas individuales de pesca, cuyo diseño precisamente se hace cargo de reducir los riesgos de colusión en las ofertas de los participantes. 
te: sólo si el teorema de Coase fuera aplicable al mercado de cuotas sería irrelevante cómo éstas se asignan (con criterios históricos o mediante una subasta), ya que eventuales transacciones futuras — que no tendrían costo alguno - garantizarían la eficiencia de la asignación final. La discusión, por lo tanto, debiera centrarse en la validez del teorema de Coase y, por lo tanto, en analizar si existen costos de transacción, si estos pueden ser removidos por cambios regulatorios y si existen asimetrías de información que, de acuerdo al teorema de Myerson-Satterthwaite, invalidan el resultado de eficiencia del teorema de Coase.

Las magnitudes de los costos de transacción y las asimetrías de información en el mercado de las cuotas de pesca debieran estudiarse en detalle y, sólo si ambas fueran insignificantes, podría argumentarse que la asignación histórica puede llevar a resultados eficientes (al igual que la subasta). A nuestro juicio, la subasta es una mejor opción por cuanto asegura la asignación inicial eficiente y, en todo caso, el peso de la prueba respecto a la inexistencia de asimetrías de información y costos de transacción debiera estar en quienes poseen las asignaciones históricas, ya que, tal como argumenta Coase, lo habitual es que existan costos de transacción, no que no existan.

La distinción entre costos de transacción y asimetrías de información es altamente relevante, pues respecto de los primeros es posible tomar medidas de política para reducirlos, ${ }^{25}$ pero ello no es viable en general para las asimetrías de información. Los agentes tienen información privada (referida, por ejemplo, a sus costos de extracción, a sus estimaciones de los niveles futuros de cuotas y de disponibilidad biológica del recurso, etc.) y su uso estratégico en el contexto de cualquier tipo de negociación hace que el resultado no sea necesariamente eficiente ${ }^{26}$. Este punto es central, y así lo destaca el trabajo de McKelvey y Page (1999):

${ }^{25}$ Sobre la conveniencia de reducir los costos de transacción no hay debate; reducirlos sin duda nos acerca a la eficiencia en asignación de recursos.

${ }^{26}$ Debe destacarse que si bien las asimetrías de información mencionadas son de naturaleza diferente en el sentido que en algunos casos las firmas poseen información que la otra no posee ( $v . g$., respecto a sus costos) y en otros ambas partes tienen estimaciones propias respecto a la evolución futura de variables comunes (v.g., la evolución de la cuota), desde una perspectiva teórica y en cuanto a su relevancia para la validez del teorema de Myerson-Satterthwaite ambos tipos de asimetría son equivalentes. En definitiva, ambos impactan sobre el valor esperado que cada firma asigna al objeto y a la distribución que estima tiene la otra firma. 
A diferencia de los costos de transacción, las ineficiencias y sesgos por derechos de propiedad debidos a la existencia de información incompleta no pueden ser eliminados mediante políticas diseñadas para facilitar las negociaciones, dado que estas ineficiencias persistirán en cualquier juego que se plantee, incluso si no hay costos de negociar ${ }^{27,28}$.

Las consecuencias de una incorrecta apreciación de la importancia de las asimetrías de información son también discutidas en el mismo trabajo:

Quienes respaldan el teorema de Coase argumentan que la existencia de costos de transacción impide que se cumplan sus propiedades de invarianza y eficiencia (de la asignación resultante). Sin embargo, igual se argumenta que el teorema de Coase tiene relevancia para el diseño de políticas por cuanto los costos de transacción son vistos como fricciones. Si la fricción puede eliminarse, sigue el argumento, entonces uno se acerca a las predicciones del caso ideal - las relativas al modelo sin costos de transacción. Esta interpretación tiene implicancias de política, puesto que sugiere que la manera de evitar en el mundo real los sesgos que generan la asignación de derechos de propiedad y la información privada es reduciendo las barreras de comunicación y negociación en lugar de modificar la asignación de derechos de propiedad. Sin embargo, nuestro análisis sugiere que esta interpretación es incorrecta. El valor de la información privada acerca de las propias preferencias persiste independientemente de cuán sencillo sea comunicarse o negociar con otros agentes, y por lo tanto no debiera esperarse que tales remedios eliminen los sesgos en los resultados debido a los efectos de la información privada ${ }^{29}$.

La conclusión lógica de la existencia de asimetrías de información es que la asignación inicial sí importa para la asignación final. La

${ }^{27}$ Traducción de los autores, p. 235.

28 De hecho, entre sus propuestas para reducir costos de transacción, el TDLC incluye una sola que apunta a mitigar problemas de información al sugerir la implementación de un mercado de intercambio formal de cuotas individuales, basado en un registro público de sus titulares, transferencias y gravámenes, con información respecto del precio y condiciones relevantes de cada transacción.

${ }^{29}$ Traducción de los autores, p. 247. 
existencia de asimetrías de información genera un sesgo en la asignación final hacia quien tiene el derecho de propiedad inicialmente; éste será quien, en caso de tratarse de un bien indivisible, retendrá con probabilidad positiva el bien aun cuando otro lo valore más o, en el caso de un bien divisible, retendrá una proporción del mismo mayor que lo eficiente. Por lo tanto, resulta de primer orden de importancia que la asignación inicial sea eficiente ${ }^{30}$.

Las subastas son mecanismos ad hoc para contextos de información asimétrica y, de estar bien diseñadas, garantizan la asignación eficiente de los objetos subastados ${ }^{31}$. Por lo tanto, sólo si estuviéramos seguros de que el mercado de cuotas de pesca (una vez realizadas las reformas legislativas al funcionamiento del mismo) fuera a operar sin costos de transacción y que por algún motivo desconocido las asimetrías de información entre los actores fueran a desaparecer (o simplemente no existieran), sólo bajo estos supuestos (y obviando consideraciones no relacionadas a la eficiencia económica) sería razonable no recomendar que la asignación inicial de las cuotas se realice mediante subastas.

En un contexto en el que, lógicamente, no estamos seguros de que estos supuestos sean realistas, cabe reflexionar acerca de cuáles son los costos y probabilidades de cometer uno u otro tipo de error. Es decir, ¿cuál sería el costo de mantener la asignación actual en circunstancias que ésta es ineficiente? ¿Cuál sería el costo de realizar una subasta en circunstancias que la asignación actual sea eficiente? La respuesta a la

${ }^{30}$ Debe recalcarse que el concepto de asimetría de información relevante no tiene que ver necesariamente con características del bien a transar; ellas son relevantes y pueden agravar el problema, pero no son necesarias. Lo que en definitiva es relevante es que exista información privada acerca de las propias preferencias, la que puede derivarse tanto de un distinto conocimiento del bien a transar como de otros factores ( $v . g$. la utilización de técnicas de producción diferentes o la existencia de economías de ámbito y/o escala diferentes que cada firma, respecto de la otra, puede estimar sólo imprecisamente).

${ }^{31}$ El hecho de que el subastador sea el Estado y por lo tanto, en el caso particular de las cuotas de pesca, tenga necesariamente una valoración inferior que quienes participarían de la subasta. Por ello, el supuesto de que la máxima valoración posible del vendedor sea mayor que la mínima del comprador no se cumple y, por lo tanto, el resultado de ineficiencia de Myerson-Satterthwaite no es aplicable en el caso de una subasta. Sí aplicaría, en cambio, si fuera un privado quien quisiera subastar su cuota ya que, en la búsqueda de maximización de su beneficio esperado, tendría el incentivo a establecer un precio de reserva que podría evitar transacciones eficientes. 
segunda pregunta es sencilla: simplemente el costo asociado a la realización de la subasta está acotado sólo a su costo administrativo, sin mayores consecuencias económicas sobre la industria, ya que la asignación que resulte de esta subasta debiera ser idéntica o muy similar a la actual si ésta resultara ser eficiente. La respuesta a la primera es claramente más difícil e incierta, ya que se relaciona con la magnitud de la ineficiencia de la asignación actual o de la que resultara del funcionamiento del mercado una vez reducidos los costos de transacción.

Los costos de transacción del mercado y las asimetrías de información existentes entre incumbents de distinto tamaño (y diferente capacidad de afectar las políticas del sector como la determinación de la cuota global) o entre incumbents y potenciales entrantes pueden no derivar de prácticas ilegales, pero no por ello dejan de tener un efecto negativo en la eficiencia productiva del sector. Es válido, por lo tanto, desde la perspectiva de políticas públicas plantearse cuál es el mejor mecanismo de asignación inicial de cuotas (más allá de todas las medidas que se tomen para facilitar su transferibilidad posterior). Adicionalmente, dada la alta concentración de mercado existente en la actualidad, la realización de subastas periódicas de fracciones de cuotas sería un mecanismo que generaría información de mercado relevante, dando "profundidad" al mercado de cuotas y tendría la ventaja adicional de dificultar el sostenimiento de potenciales acuerdos colusivos.

Un argumento en contra de la realización periódica de subastas que ha sido sostenido por los principales industriales pesqueros en Chile, y algunos economistas que apoyan esta hipótesis, se refiere a la necesidad de garantizar derechos de propiedad, de modo de generar los incentivos apropiados para las inversiones ${ }^{32}$. Ello sería necesario, de acuerdo a este argumento, porque existen algunas inversiones de largo plazo que serían irreversibles $\mathrm{y}$, por lo tanto, tienen carácter de costo hundido. Al respecto, cabe realizar dos alcances que ponen en duda esta postura.

En primer lugar, obviamente, cabe preguntarse cuáles son esas inversiones que representan costos hundidos (es decir, inversiones que si quién las hizo no continuara en el mercado sería incapaz de recuperar). En algunas pesquerías, tal como reconoce Peña-Torres (2002), éstas pueden asociarse a actividades de marketing y de comercializa-

${ }^{32}$ Véase, por ejemplo, Rodríguez (2010). 
ción como son la construcción de redes comerciales en el exterior. Esto seguramente es válido para ciertos bienes con alto valor agregado, pero no sería mayormente relevante para bienes que son commodities como los distintos tipos de harinas y aceites de pescado. Adicionalmente, si hubiera costos hundidos en las plantas de procesamiento, estos serían irrelevantes si existe competencia en la extracción del recurso entre industriales (a la que además debe sumarse la de los pescadores artesanales), ¿por qué sería problemático perder la eventual porción de la cuota si de todas maneras es posible comprar el recurso y, de esta manera, seguir operando las plantas y rentabilizando las inversiones hundidas? $\mathrm{O}$ bien el argumento es inválido o bien el mercado del insumo (en el que participan quienes tienen las cuotas) no es tan competitivo.

En segundo lugar, y adicionalmente, si los costos hundidos cualquiera sea su origen fueran importantes, entonces debieran dar una ventaja de costos relevante a las firmas establecidas por sobre los potenciales entrantes, lo que debiera redundar en que las mismas se adjudiquen las cuotas correspondientes en el proceso de licitación.

\section{Conclusiones}

Este artículo analiza la conveniencia de que la asignación de las cuotas individuales de pesca, cuyos derechos de propiedad suponemos que no han sido asignados a perpetuidad sino que vencen en el 2012, se realice de acuerdo a criterios históricos o mediante el desarrollo de una subasta, enfatizando el rol de dos elementos: los costos de transacción y las asimetrías de información.

Precisamente los argumentos basados en el teorema de Coase han sido utilizados ante el TDLC para argumentar que el criterio de asignación inicial es irrelevante (y, por lo tanto, asignar de acuerdo a criterios históricos sería apropiado) y que debe perfeccionarse la legislación para reducir los costos de transacción. Naturalmente, este último punto es indiscutible, pero no invalida en absoluto la discusión sobre la asignación inicial de las cuotas. Sólo si los costos de transacción se eliminasen $y$ no existieran asimetrías de información de ningún tipo entre los participantes de este mercado podría argumentarse, basándose en el teorema de Coase, que las cuotas pueden asignarse por criterios históricos.

Desde una perspectiva de política pública, y analizando el problema sólo desde esta perspectiva, la decisión de cómo asignar las cuo- 
tas de pesca debiera sopesar dos elementos: el costo de organizar una subasta versus el costo de, con cierta probabilidad, realizar una asignación inicial ineficiente en un mercado concentrado en el que los costos de transacción existen (aun cuando puedan reducirse) y las asimetrías de información, en parte por el hecho de haber pocos actores, son también relevantes.

Nuestro trabajo presupone que el costo de diseñar una subasta que garantice la eficiencia económica, esto es que quien más valora se quede con las cuotas de pesca, es acotado; mientras que el costo de asignar inadecuadamente y a perpetuidad derechos de propiedad que aún no han sido asignados podría ser muy superior. Refuerza nuestra creencia de que podría ser ésta la situación en la industria pesquera su alta concentración de mercado y la evidencia, teórica y empírica, de que a mayor concentración menor liquidez, lo que llevaría necesariamente a que cualquier transacción ex post requiera de una negociación bilateral entre el poseedor de los derechos y un potencial entrante al mercado.

\section{REFERENCIAS}

Akerlof, George. "The Market for 'Lemons': Quality Uncertainty and the Market Mechanism”. Quarterly Journal of Economics Vol. 84(3), 1970.

Bettis, Carr, Jeffrey Coles y Michael Lemmon. "Corporate Policies Restricting Trading by Insiders". Journal of Financial Economics Vol. 57(2), 2000.

Coase, Ronald. "The Nature of the Firm". Economica Vol. 4(16), 1937. "The Federal Communications Commission". Journal of Law and Economics Vol. 2, 1959.

"The Problem of Social Cost". Journal of Law and Economics Vol. 3, 1960.

The Firm, The Market, and The Law. The University of Chicago Press, 1988.

\footnotetext{
"The Institutional Structure of Production". American Economic Review Vol. 82(4), 1992.
}

Cramton, Peter, Robert Gibbons y Paul Klemperer. "Dissolving a Partnership Efficiently". Econometrica Vol. 55(3), 1987.

Demsetz, Harold. "The Cost of Transacting". Quarterly Journal of Economics Vol. 82 (1), 1968.

Easly, David y Maureen O'Hara. "Prices, Trade Size and Information in Security Markets". Journal of Financial Economics Vol. 33, 1987.

Fudenberg, David y Jean Tirole. Game Theory, The MIT Press, 1991.

Glosten, Lawrence y Paul Milgrom. "Bid, Ask and Transaction Prices in a Specialist Market with Heterogeneously Informed Traders". Journal of Financial Economics Vol. 14(1), 1985. 
Grossman, Sanford y Joseph Stiglitz. "On the Impossibility of Informationally Efficient Markets”. American Economic Review Vol. 70(3), 1980.

Harrison, Rodrigo. "Estudio de Organización Industrial del Mercado de Pesca Industrial en Chile". Informe presentado al Tribunal de Defensa de la Libre Competencia, 2010.

Holmström, Bengt y Jean Tirole. "Market Liquidity and Performance Monitoring". Journal of Political Economy Vol. 101(4), 1993.

Jaffe, Jeffrey "Special Information and Insider Trading". Journal of Business Vol. 47(3), 1974.

Klemperer, Paul. Auctions: Theory and Practice. Princeton University Press, 2004.

Krishna, Vijay. Auction Theory. Academic Press, 2002.

Lakonishok, Joseph e Inmoo Lee. “Are Insiders Trades Informative?”. Review of Financial Studies Vol. 14(1), 2001.

Lin, Ji-Chai y John Howe. "Insider Trading in the OTC Market". Journal of Finance Vol. 45(4), 1990.

Lota Protein S.A. Consulta de la pesquera Lota Protein S.A. al Tribunal de Defensa de la Libre Competencia (sobre régimen de acceso a los recursos pesqueros) 2010. Disponible en www.tdlc.cl.

Magill, Michael y Martine Quinzii. Theory of Incomplete Markets. MIT Press, 1996.

McAfee, Preston. "Four Issues in Auctions and Market Design". Revista de Análisis Económico Vol. 13(1), 1998.

McKelvey Richard y Talbot Page. "Taking the Coase Theorem Seriously". Economics and Philosophy Vol. 15(2), 1999.

"An Experimental Study of the Effect of Private Information in the Coase Theorem". Experimental Economics Vol. 3(3), 2000.

_ "Status Quo Bias in Bargaining: An Extension of the MyersonSatterthwaite Theorem with an Application to the Coase Theorem". Journal of Economic Theory Vol. 107(2), 2002.

McMillan, John. "Selling Spectrum Rights". Journal of Economics Perspectives Vol. 8(3), 1994.

Merton, Robert. "A Simple Model of Capital Market Equilibrium with Incomplete Information”. Journal of Finance Vol. 42(3), 1987.

Milgrom, Paul. Putting Auction Theory to Work. Cambridge University Press, 2004.

Montero, Juan Pablo. “Asignación de Cuotas de Pesca y Libre Competencia”. Informe presentado al Tribunal de Defensa de la Libre Competencia, 2010.

Myerson, Roger y Mark Satterthwaite. "Efficient Mechanisms for Bilateral Trading". Journal of Economic Theory Vol. 29(2), 1983.

Peña-Torres, Julio. "Debates sobre Cuotas Individuales Transferibles: ¿"Privatizando" el Mar? ¿Subsidios? O ¿Muerte Anunciada de la Pesca Extractiva en Chile?". Estudios Públicos 86 (otoño 2002).

Peña-Torres, Julio y Gabriel Fernández. "Auctions, Entry Deterrence and Divisibility of the Object for Sale". Documento de Trabajo 247, ILADES-Universidad Alberto Hurtado, 2010. 
Rodríguez, Jorge. "A Potenciar las Cuotas de Pesca". En Observatorio Económico, No 41, 2010, Universidad Alberto Hurtado, Santiago.

Rubin, Amir. "Ownership Level, Ownership Concentration and Liquidity". Journal of Financial Markets Vol. 10(3), 2007.

Stigler, George. "Two Notes on the Coase Theorem". The Yale Law Journal Vol. 99(3), 1989.

Tribunal de Defensa de la Libre Competencia. Proposición N 12, 2010.

Tirole, Jean. Corporate Finance. MIT Press, 2006.

Villena, Mauricio, Jorge Niño y Franco Zechetti. "Valoración Económica de las Cuotas de Pesca". Informe presentado al Tribunal de Defensa de la Libre Competencia, 2010. 